\title{
The role of PNPLA3 (rs738409) c $>$ g variant on histological progression of non-alcoholic fatty liver disease
}

\author{
Ramazan Idilman ${ }^{1,2, *}$, (i) Senem Ceren Karatayli ${ }^{2,3}$, (i) Gokhan Kabacam ${ }^{1}$, (i) Berna Savas ${ }^{4}$, \\ (1) Atilla Halil Elhan 5 , (1) A Mithat Bozdayi² \\ ${ }^{1}$ Department of Gastroenterology, Ankara University School of Medicine, Ankara, Turkey; ${ }^{2}$ Ankara University Hepatology Institute, Ankara, Turkey; \\ ${ }^{3}$ Department of Medicine II, Saarland University Medical Center, Homburg, Germany; ${ }^{4}$ Department of Pathology, Ankara University School of Medicine, Ankara, \\ Turkey; ${ }^{5}$ Department of Biostatistics, Ankara University, Ankara, Turkey
}

\begin{abstract}
Background and Aim: The present study aims to investigate the role of genetic variability of the PNPLA3 gene (adiponectin) in predisposition to non-alcoholic fatty liver disease (NAFLD) by comparing NAFLD patients to healthy controls and to investigate any impact of the PNPLA3 genetic variability on the natural course of the disease.
\end{abstract}

Materials and Methods: This cohort consisted of 174 patients with biopsy-proven NAFLD and 151 healthy controls. DNA was extracted from peripheral blood and the rs738409 $\mathrm{C}>\mathrm{G}$ single nucleotide polymorphism was assessed using PCR-DNA sequencing.

Results: The frequency distribution of the GG genotype was significantly higher in NAFLD patients than in controls $(\mathrm{p}=0.01)$. In patients with NAFLD, the GG genotype was associated with lower platelet counts $(p=0.001)$, the presence of steatohepatitis $(\mathrm{p}=0.04)$ and hepatic fibrosis $(\mathrm{p}=0.016)$. After adjustment for age, gender, obesity, and diabetes mellitus, the GG genotype was an independent predictor of significant hepatic fibrosis (adjusted odds ratio $=3.031 \mathrm{p}=0.012$ ). From the baseline to sequential liver biopsies, the progression of NAS in NAFLD patients was slightly higher in the GG genotype than that of CC and GG genotypes ( $\mathrm{p}=0.18$ ).

Conclusion: The PNPLA3 GG genotype is a predisposing factor for the development of hepatic steatosis in NAFLD patients and related to a more severe liver disease.

Keywords: Genome-wide association studies (GWAS); nonalcoholic fatty liver disease; PNPLA3; steatohepatitis.

How to cite this article: Idilman R, Karatayli SC, Kabacam G, Savas B, Elhan AH, Bozdayi AM. The role of PNPLA3 (rs738409) $\mathrm{c}>\mathrm{g}$ variant on histological progression of non-alcoholic fatty liver disease. Hepatology Forum 2020; 1(3):82-87.

*Ramazan Idilman is a member of the Science Academy (BA)

Received: August 28, 2020; Accepted: September 05, 2020; Available online: September 21, 2020

Corresponding author: Ramazan Idilman; Ankara University Faculty of Medicine, Department of Gastroenterology, Ankara, Turkey

Phone: +90 312363 6213; e-mail: idilman@medicine.ankara.edu.tr

(c) (1) OPEN ACCESS

c. This work is licensed under a Creative Commons Attribution-NonCommercial 4.0 International License.

(C) Copyright 2020 by Hepatology Forum - Available online at www.hepatologyforum.org

\section{Introduction}

Nonalcoholic fatty liver disease (NAFLD) is one of the most common liver disorders worldwide. ${ }^{[1-4]}$ NAFLD is the spectrum of liver disease ranging from hepatic steatosis to non-alcoholic steatohepatitis (NASH), hepatic fibrosis, cirrhosis and liver cancer. ${ }^{[1-4]}$ NAFLD affects approximately $25 \%$ of the general population. ${ }^{[5,6]}$ Obesity, diabetes, race, ethnic differences and genetic predispositions affect its prevalence and natural course of the disease..$^{[5-8]}$ The prevalence of NAFLD has increased gradually during the past two decades. ${ }^{[6]}$ The increasing prevalence of obesity, DM, and associated metabolic syndromes increases the risk of NAFLD-related cirrhosis. ${ }^{[6]}$ In Turkey, the prevalence of obesity was 36\%. ${ }^{[7]}$ Previous studies reported that the NAFLD prevalence in Turkey is around $10.6 \%-23.2 \%{ }^{[9]}$ however, no reliable data regarding the prevalence of NAFLD are available.

Patatin-like phospholipase domain-containing (PNPLA) proteins, a mammalian family of lipid hydrolase, are members of the patatin family. ${ }^{[10-12]}$ The human genome expresses nine PNPLA proteins (PNPLA1-9), which serve critical roles in lipid metabolism and its signaling, and the maintenance of membrane integrity, and regulation of energy metabolism. ${ }^{[10-13]}$ PNPLA3, as adiponutrin, is expressed mainly in the liver and adipose tissues of humans. Mammalian nutritional status regulates the hepatic expression of the protein both at the transcriptional and post-translational levels. ${ }^{[11-14]}$ During fasting, hepatic PNLPA3 mRNA levels are low; however, they increase after carbohydrate feeding. ${ }^{[14]}$ The biochemical function of the PNPLA3 remains not well understood. PNLPA3 plays a role in the hydrolysis of glycerolipids and has lipase activity against triglycerides. ${ }^{[10-14]}$ The nonsynonymous mutation (I148M) of this gene causes a loss of function that predisposes to steatosis as a result of decreased triglyceride hydrolysis in hepatocytes. ${ }^{[11-13]}$ Several groups reported a mutation in the PNPLA3 gene (adiponutrin, rs738409 $\mathrm{C}>\mathrm{G}$ ) encoding isoleucine to methionine substitution at the 148 position that is associated with the prevalence and severity of NAFLD and alcoholic liver disease, and chronic hepatitis, fibrosis, and cirrhosis and its complications included hepatocellular carcinoma. ${ }^{[15-20]}$

The present study aims to investigate the role of genetic variability of the PNPLA3 gene (adiponutrin, rs738409) in predisposition to NAFLD by comparing NAFLD patients to healthy controls and investigate any impact of the PNPLA3 genetic variability on the natural course of the disease on longitudinal liver biopsies in such patients. 


\section{Materials and Methods}

\section{Patients}

Between May 2010 and February 2014, 174 DNA samples of consecutive patients with NAFLD, who were seen in the Ankara University School of Medicine, Department of Gastroenterology, Liver Diseases Outpatient Clinic, were analyzed. Diagnosis of NAFLD in each case was based on biochemical, radiological and histological criteria. Criteria for inclusion were: 1) age $>16$ years; 2) convincing evidence of absent or minimal alcohol consumption: $<20 \mathrm{~g}$ alcohol/day for women and $<30 \mathrm{~g}$ alcohol/day for men; 3 ) absence of confounding disease, including acute and/or chronic viral hepatitis (hepatitis A, B or C); and 4) exclusion of other forms of liver disease, including autoimmune, druginduced and metabolic liver diseases. Data were obtained from patient visit charts. Population control samples were from 151 healthy individuals who had no evidence of liver disease or any other disease, no alcohol abuse. Controls with high body mass index (BMI, $>25 \mathrm{~kg} / \mathrm{m}^{2}$ ) and an abnormal abdominal sonographic pattern were excluded from this study.

\section{Clinical and Laboratory Assessments}

Serum alanine aminotransferase (ALT), aspartate aminotransferase (AST), gamma-glutamyl transpeptidase (GGT), alkaline phosphatase, bilirubin, fasting glucose, cholesterol, triglycerides levels, and complete blood cell counts were measured by our central laboratory using standard reagents. Insulin was measured by radioimmunoassay.

\section{Histological Assessments}

Liver biopsy was performed in patients with normal and abnormal serum aminotransferases levels having an abnormal sonographic pattern as increased liver parenchyma echogenicity. All liver biopsy specimens were retrieved from the archives of the Department of Pathology, Ankara University School of Medicine. Liver biopsy material was mounted on archival slides originally prepared from $10 \%$ formalinfixed paraffin-embedded tissue and stained with hematoxylin-eosin and with Masson's trichrome stain to evaluate the fibrosis. The liver biopsy specimens were evaluated by one pathologist (BS), who has blinded to the clinical and biochemical data. Histological features of the samples were interpreted based on the criteria of Kleiner et al. ${ }^{[21]}$ Hepatic steatosis was classified from grade 0 to grade 3: Minimal steatosis, grade 0 , was defined as $<5 \%$ steatosis; mild steatosis, grade 1 as $5-33 \%$; moderate steatosis, grade 2 , as $33 \%-66 \%$; and severe steatosis, grade 3 , as $>66 \%$. Necroinflammation, either lobular or portal, was graded. Fibrosis was scored from 0 to 4 and significant fibrosis was defined as stage 2 to 4 fibrosis. NAFLD Activity Score (NAS) $(0-8)$ was calculated based on the grade of steatosis (0-3), lobular inflammation (0-3), and ballooning (0-2). ${ }^{[21]} \mathrm{NASH}$ was defined as patients with NAS $\geq 5$, while patients with $\mathrm{NAS}<3$ were diagnosed as not-NASH. ${ }^{[1]}$

\section{Genetic Analysis}

Genomic DNA samples were extracted from peripheral blood leukocytes using the high salt concentration method. ${ }^{[22]}$ Genomic DNA was amplified by PCR using the primers: 5'-GAGGGTGTATGTTAGTTCCCCGT-3' and 5'-AGCACACTTCAGAGGCCCC-3' to detect the adiponutrin/ PNPLA3 rs $738409 \mathrm{C} \rightarrow \mathrm{G}$ SNP, encoding I148M. The PCR conditions were composed of initial denaturation step at $95^{\circ} \mathrm{C}$ for five minutes (min) followed by 30 cycles of denaturation at $95^{\circ} \mathrm{C}$ for one min, annealing at $62^{\circ} \mathrm{C}$ for one min and extension at $72^{\circ} \mathrm{C}$ for one min, fol- lowed by a final step at $72^{\circ} \mathrm{C}$ for seven min. Subsequent analyses were performed using the BigDye Terminator v3.1 cycle sequencing system (PE Applied Biosystems, Foster City, CA, USA). After amplification, the cycle-sequencing products were purified by sodium acetate-ethanol precipitation. The purified products were then analyzed using an ABI 3100 genetic analyzer (Perkin Elmer, Foster City, CA, USA).

\section{Definition}

BMI was calculated as weight in kilograms divided by height in meters squared. Obesity was defined based on the World Health Organization criteria with a BMI of $25-29.9 \mathrm{~kg} / \mathrm{m}^{2}$ defining overweight and BMI $\geq 30 \mathrm{~kg} / \mathrm{m}^{2}$ defining obesity. ${ }^{[23]} \mathrm{IR}$ was calculated on the basis of fasting plasma glucose and insulin values using the homeostasis model assessment-insulin resistance method (HOMA-IR: plasma glucose $(\mathrm{mg} / \mathrm{dL}) \mathrm{x}$ insulin $(\mu \mathrm{u} / \mathrm{ml}) / 405) .^{[24]}$

After the diagnosis of NAFLD was confirmed, the management was focused in the following areas: the establishment of an appropriate diet, including a conventional diet of $25 \mathrm{kcal} / \mathrm{kg}$ x ideal body weight $(\mathrm{kg})$ with three meals per day containing $60 \%$ carbohydrate, $25 \%$ fat and $15 \%$ protein and an exercise program, including walking (initially as 300 steps per day for three days, thereafter adding 500 steps at 3-day intervals until a level of 10000 steps was attained) and/or jogging (20 minutes twice a day); ${ }^{[25,26]}$ improvement in associated conditions, such as diabetes mellitus, IR, and moderate/severe hyperlipidemia; and discontinuation of potentially hepatotoxic drugs, such as herbal medicine. The dietitian interviewed all subjects, and the same diet and exercise program was suggested. The dietitian and one of the authors monitored patient compliance with the diet and exercise program during the follow-up period using verbal communication.

\section{Follow-up}

All subjects were seen in the fourth week and in three or six-month intervals thereafter in the Outpatient Clinic. Laboratory tests were performed during the follow-up period. Second liver biopsy was optional and was performed after one year of the follow-up period for the evaluation of the liver histology and treatment effect when the patient was accepted.

\section{Statistical Analysis}

Categorical variables were evaluated using Chi-square test or Fisher's exact test, where applicable. Differences among the groups for baseline clinical and laboratory characteristics were evaluated using KruskalWallis variance analysis. When there were two groups, the Mann-Whitney $U$ test was used. To define risk factors of the outcome variable (steatosis, NASH), multiple logistic regression analysis was used. SPSS for Windows 11.5 was used for statistical analysis. P-value less than 0.05 was considered significant.

\section{Results}

The present cohort consisted of 325 subjects from 174 individuals with biopsy-proven NAFLD (M/F: 89/85, mean age: $47.9 \pm 10.5$ year) and 151 healthy controls (M/F: 45/106, mean age: $31.1 \pm 8.8$ years). NAFLD patients were older with male predominance $(\mathrm{p}<0.001$ and $\mathrm{p}<0.001$, respectively). At the time of the diagnosis of NAFLD, the median BMI was $29.2 \mathrm{~kg} / \mathrm{m}^{2}$ (36\% were obese), and $23 \%$ of the patients had diabetes mellitus, 58\% IR (HOMA score $>2.7$ ), 49\% hyperlipidemia, and 24\% hypertension. Median serum AST, ALT and GGT levels were 32 
Table 1. Characteristics of all patients with NAFLD

\begin{tabular}{ll}
\hline Age (years) & $47.9 \pm 10.5(49)$ \\
Gender (Male/Female) & $89(51.1 \%) / 85(48.9 \%)$ \\
\hline $\mathrm{BMI}\left(\mathrm{kg} / \mathrm{m}^{2}\right)$ & $30.0 \pm 5.5(29.2)$ \\
Diabetes mellitus & $23.3 \%$ \\
Hypertension & $23.6 \%$ \\
Hyperlipidemia & $49 \%$ \\
\hline Insulin resistance (HOMA score>2.7) & $58 \%$ \\
\hline Serum AST levels (normal range: $10-37 \mathrm{U} / \mathrm{L})$ & $38.8 \pm 21.5(32)$ \\
Serum ALT levels (normal range: $10-37 \mathrm{U} / \mathrm{L})$ & $61.6 \pm 40.1(50)$ \\
Serum GGT levels (normal range: 0-55 U/L) & $55.7 \pm 54.5(38)$ \\
Serum total bilirubin levels & \\
(normal range: $0.2-1.1 \mathrm{mg} / \mathrm{dL})$ & $0.84 \pm 0.46(0.7)$ \\
Serum platelet counts (normal range: X10 $/ \mathrm{L})$ & $245.8 \pm 72.8(234)$ \\
\hline
\end{tabular}

Mean $\pm S D$ (median); SD: Standard deviation; NAFDL: Non-alcoholic fatty liver disease; BMI: Body mass index; AST: Aspartate aminotransferase; ALT: Serum alanine aminotransferase; GGT: Gamma-glutamyl transpeptidase.

Table 2. The baseline histopathological characteristics of 174 patients with NAFLD

\begin{tabular}{lll}
\hline & Mean \pm SD & Median \\
\hline NAS & $4.7 \pm 1.5$ & 5.0 \\
Steatosis & $1.97 \pm 1.04$ & 2.0 \\
Ballooning & $1.61 \pm 0.52$ & 2.0 \\
Lobular inflammation & $1.07 \pm 0.52$ & 1.0 \\
Fibrosis & $0.79 \pm 0.96$ & 0.5 \\
& $\mathbf{n}$ & $\%$ \\
\hline NASH diagnosis (NAS $\geq 5)$ & 104 & 59.8 \\
\hline NAS: NAFLD Activity Score; NAFDL: Non-alcoholic fatty liver disease.
\end{tabular}

U/L (range: 10-133 U/L), 50 U/L (range: 16-235 U/L) and 38 (range: 10-442 U/L), respectively. The characteristics of all patients with NAFLD are shown in Table 1.

The median NAS of the initial 174 liver biopsies was 5.0 (range: 1 to 8 ), median hepatic steatosis 2 (0-3), ballooning 2 (1-3), lobular inflammation $1(0-3)$, portal inflammation $0(0-2)$, and fibrosis $0.5(0-4)$. Of those, $22.4 \%$ of the biopsy samples revealed grade $1,25.3 \%$ grade 2 and $41.4 \%$ grade 3 hepatic steatosis. Ballooning was observed $59.2 \%$ of the samples: few balloon cells (mild-moderate) in $57.5 \%$ and many balloon cells (severe) in $1.7 \%$, whereas $40.8 \%$ of the samples showed no ballooning cell. Lobular inflammation was graded as follows: $8.6 \%$ of the patients $(n=15)$ had no necroinflammation, $77.6 \%$ had grade 1 , $12.1 \%$ had grade 2 , and the remaining $1.7 \%$ had grade 3 necroinflammation. Of note, $50.0 \%$ of the samples $(n=87)$ revealed the presence of fibrosis: $57.5 \%$ of those (50/87) had F1 and $42.5 \%$ (37/87) showed significant fibrosis $(\geq F 2)$. A histological diagnosis of NASH (NAS $\geq 5$ ) was obtained in $60 \%$ of the patients $(104 / 174)$. The histological features of the patients are shown in Table 2 .

\section{Association with Clinical and Biochemical Parameters}

Among NAFLD patients, 47.7\% ( $\mathrm{n}=83)$ had GG, 27.6\% $(\mathrm{n}=48)$ had $\mathrm{CC}$ and $24.7 \%(\mathrm{n}=43)$ had CG genotype, compared with $31 \%(\mathrm{n}=47)$
Table 3. With logistic regression analysis, the association of the GG genotype with advanced hepatic fibrosis

\begin{tabular}{lllll}
\hline Variables & Adjusted OR & \multicolumn{2}{c}{$95.0 \% \mathbf{C l}$} & p \\
\cline { 3 - 4 } & & Lower & Upper & \\
\hline Age & 1.023 & 0.978 & 1.070 & $>0.05$ \\
Gender & 1.686 & 0.669 & 4.253 & $>0.05$ \\
Diabetes & 2.377 & 0.968 & 5.841 & $>0.05$ \\
BMI & 1.435 & 0.607 & 3.390 & $>0.05$ \\
GG genotype & 3.0 & 1.279 & 7.183 & 0.012 \\
\hline
\end{tabular}

OR: Odd ratios; $\mathrm{Cl}$ : Confidence interval; BMI: Body mass index.

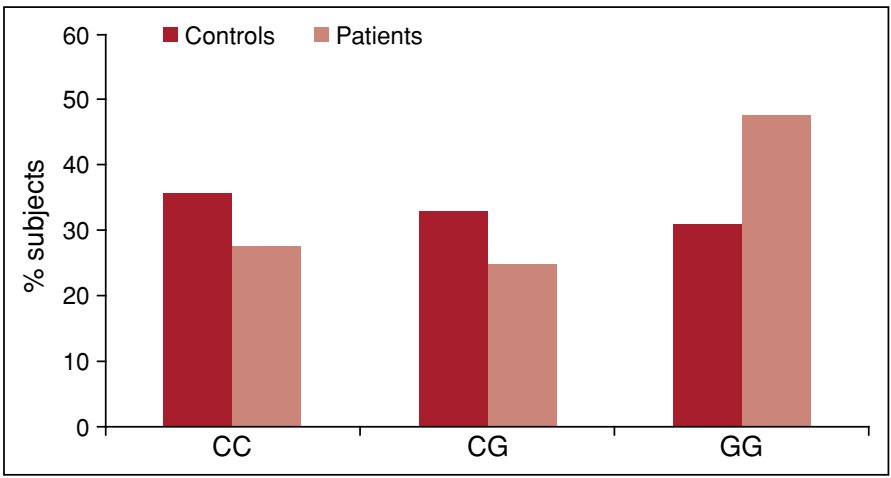

Figure 1. The frequency distributions of the PNPLA3 gene, CC, CG and GG genotypes in NAFLD patients compared to healthy controls.

GG, 36\% $(n=54) \mathrm{CC}$ and $33 \%(\mathrm{n}=50) \mathrm{CG}$ genotype frequencies among healthy controls, respectively (Fig. 1). The frequency distribution of the GG genotype was significantly higher in NAFLD patients than in healthy controls $(48.0 \%$ vs. $31.0 \%, \mathrm{p}=0.01)$ (Fig. 1). Among patients' baseline characteristics, the GG genotype was only associated with low platelet counts $(226.8 \pm 57.1$ vs. $263.5 \pm 81.2, \mathrm{p}=0.001)$.

\section{Association with Liver Histology}

The GG genotype was significantly associated with the presence of steatohepatitis $(56 / 83,67.5 \%$ vs. $48 / 91,52.7 \%$; $\mathrm{p}=0.048)$ and hepatic fibrosis $(1.01 \pm 1.10$ vs. $0.06 \pm 0.77, \mathrm{p}=0.016)$. No association was found with the severity of steatosis (grades 2 and 3), hepatocellular ballooning, or lobular or portal inflammation. In addition, significant fibrosis $(\geq$ F2) was significantly associated with the GG genotype $(25 / 83,30.1 \%$ vs. $12 / 91,13.2 \%$; $\mathrm{p}=0.006$ ). After adjustment for age, gender, obesity and diabetes mellitus, the GG genotype was significantly associated with significant fibrosis [adjusted odds ratio $[\mathrm{OR}]=3.0,95 \%$ confidence interval $(\mathrm{CI})=1.279-7.183 ; \mathrm{p}=0.012]($ Table 3$)$.

\section{Association with Histological Progression}

Fifty-one NAFLD patients had sequential liver biopsies; 34 patients had NASH on their initial biopsies. The median interval between the two biopsies was 44 months (range, 12-120 months). The median NAS of the initial 51 liver biopsies was 4.96 (range: 2 to 8 ), hepatic steatosis 2 (0-3), ballooning $2(0-3)$, lobular inflammation $1(0-3)$, portal inflammation $0(0-2)$, and fibrosis $0(0-4)$. On their second liver biopsies, 29 patients had NASH; the median NAS was 5.0 (range: 2 to 7), hepatic 
Table 4. The GG genotype did not influence disease progression in patients with NAFLD between the two sequential liver biopsies

\begin{tabular}{|c|c|c|c|c|c|}
\hline & \multicolumn{2}{|c|}{51 NAFLD patients } & \multicolumn{2}{|c|}{34 NASH patients } & \multirow[b]{2}{*}{$\mathbf{p}$} \\
\hline & GG (\%) & $\mathrm{CC}+\mathrm{CG}(\%)$ & GG (\%) & $\mathrm{CC}+\mathrm{CG}(\%)$ & \\
\hline \multicolumn{6}{|l|}{ NAS } \\
\hline Stabilized and regressed & 64.0 & 80.8 & 72.2 & 75.0 & $\mathrm{p}=0.180$ \\
\hline Progression & 36.0 & 19.2 & 27.8 & 25.0 & $\mathrm{p}=1.0$ \\
\hline \multicolumn{6}{|l|}{ Steatosis } \\
\hline Stabilized and regressed & 88.0 & 80.8 & 88.9 & 81.3 & $\mathrm{p}=0.703$ \\
\hline Progression & 12.0 & 19.2 & 11.1 & 18.8 & $p=0.64 \varepsilon$ \\
\hline \multicolumn{6}{|l|}{ Ballooning } \\
\hline Stabilized and regressed & 72.0 & 84.6 & 77.8 & 87.5 & $\mathrm{p}=0.274$ \\
\hline Progression & 28.0 & 15.4 & 22.2 & 12.5 & $\mathrm{p}=0.66 \mathrm{c}$ \\
\hline \multicolumn{6}{|l|}{ Lobular Inflammation } \\
\hline Stabilized and regressed & 88.0 & 80.8 & 88.9 & 81.3 & $\mathrm{p}=0.703$ \\
\hline Progression & 12.0 & 19.2 & 11.1 & 18.8 & $p=0.64 \varepsilon$ \\
\hline \multicolumn{6}{|l|}{ Fibrosis } \\
\hline Stabilized and regressed & 60.0 & 61.5 & 61.1 & 56.3 & $\mathrm{p}=0.910$ \\
\hline Progression & 40.0 & 38.5 & 38.9 & 43.8 & $\mathrm{p}=0.774$ \\
\hline
\end{tabular}

steatosis $2(0-3)$, ballooning $2(1-3)$, lobular inflammation $1(0-2)$, portal inflammation $0(0-2)$, and fibrosis $1(0-4)$.

Between the two biopsies, hepatic steatosis regressed in $15.7 \%$ of the samples, showed no changed in $52.9 \%$ and progressed in $31.4 \%$; hepatocellular ballooning regressed in $21.6 \%$, stabilized in $49.0 \%$ and progressed in $29.4 \%$; lobular inflammation regressed in $15.7 \%$, stabilized in $58.8 \%$ and progressed in $25.5 \%$; NAS regressed in $27.5 \%$, stabilized in $31.4 \%$ and progressed in $41.1 \%$; and fibrosis regressed in $39.2 \%$, stabilized in $45.1 \%$ and progressed in $15.7 \%$.

In NAFLD patients, from the baseline to sequential liver biopsies, the progression of NAS slightly higher in the GG genotype than that of $\mathrm{CC}$ and $\mathrm{GG}$ genotypes ( $36 \%$ vs. $19.2 \%, \mathrm{p}=0.180$ ). However, progression of fibrosis did not differ ( $40.0 \%$ vs. $38.5 \%, p=0.910)$. No significant differences concerning NAS and fibrosis progression among genotypes of NASH patients were observed $(p>0.05)$. The progression of NAS and fibrosis in NASH patients with GG and other genotypes were $27.8 \%$ and $38.9 \%$, and $25 \%$ and $43.8 \%$ ( $\mathrm{p}=1.0$ and $\mathrm{p}=0.774$ ), respectively (Table 4 ).

\section{Discussion}

This study aimed to investigate the genetic variability of the PNPLA3 gene in a Turkish NAFLD patient cohort with variations in demographic, anthropometric and environmental factors. The frequency distributions of the PNPLA3 gene, CC, CG and GG genotypes in NAFLD patients and controls were $28 \%$ and $25 \%, 48 \%$ and $36 \%$, and $33 \%$ and $31 \%$, respectively. The GG genotype was more prevalent in NAFLD patients compared to a healthy population $(48.0 \%$ vs. $31.0 \%, \mathrm{p}=0.01)$. This result confirms the previous studies that showed a significant association between the GG genotype of the PNPLA3 gene and fatty liver disease. ${ }^{[15-18,20,27-29]}$ This result suggests that the GG genotype exerts a strong influence on liver fat accumulation.

The GG genotype represents a loss of function of adiponutrin, which causes failure in the breakdown of triglycerides during hyperinsulinemic states. ${ }^{[1-14]}$ The reported data regarding the association between the GG genotype and abnormalities in biochemical parameters, including BMI, hypertriglyceridemia and elevated serum aminotransferases levels in NAFLD patients are conflicting. Some data were able to confirm these findings, ${ }^{[13,15,27-31]}$ but other data were unable. $[17,29,30,32,33]$ Romeo et al. ${ }^{[15]}$ found a significantly increased hepatic triglyceride content in individuals with GG genotype. Kollerits et al. ${ }^{[13]}$ reported a significant association of the GG genotype with serum total cholesterol, non-high-density lipoprotein and low-density lipoprotein levels and suggested that adiponutrin might disturb lipid metabolism. Interestingly, in contrast to these findings, other studies ${ }^{[17,29,32,33]}$ demonstrated the dissociation among the GG genotype, gender and metabolic abnormalities, including obesity, fasting glucose, insulin levels, IR and hypertriglyceridemia in NAFLD patients. In the present study, among the patients' characteristics, the GG genotype was only significantly associated with low platelet counts in patients with NAFLD ( $p=0.001)$. This discrepancy may explain the differences between the recruited patients in various studies.

An association between the GG genotype and the severity of disease in the adult and pediatric populations was reported previously. ${ }^{[20,29,34-37]}$ Valenti et al. ${ }^{[34]}$ showed that the GG genotype was strongly associated with the presence of severe steatosis $(>1)$, NASH and fibrosis stage $(>1)$. A meta-analysis study reported that NAFLD patients with GG genotype had a 3.24-fold greater risk of higher inflammation scores and a 3.20-fold greater risk of developing liver fibrosis when compared with CC genotype patients. ${ }^{[29]}$ In the present study, the GG genotype was significantly associated with the presence of steatohepatitis and hepatic fibrosis $(\mathrm{p}=0.048, \mathrm{p}=0.016$, respectively) in NAFLD patients. However, no association was found with the severity of hepatic steatosis, hepatocellular ballooning or lobular inflammation. More importantly, significant fibrosis was more common in the GG genotype than in the other genotypes $(p=0.006)$. After adjustment for age, gender, obe- 
sity, and diabetes mellitus, the risk of significant fibrosis was 3.0-fold higher in NAFLD patients with the GG genotype. These results suggest that the GG genotype of the PNPLA3 gene is associated with both liver fat accumulation and also a higher disease severity.

Advanced age ( $>50$ years), male gender, obesity, diabetes mellitus and hepatic necroinflammation have been identified previously as predictive factors associated with the severity of fibrosis and progression of disease in patients with NAFLD. ${ }^{[2,38,39]}$ Grimaudo et al. ${ }^{[20]}$ reported that NAFLD patients carrying PNPLA3 $r$ s $738409 \mathrm{G}>\mathrm{C}$ variant are at higher risk of liver-related events and death. In the present study, from baseline to second liver biopsies, the progression of NAS slightly higher in NAFLD patients with GG genotype than those of CC and GG genotypes $(p=0.18)$. However, no significant differences were observed in NASH patients $(p>0.05)$. This result indicates that a lack of association between the GG genotype of the PNPLA3 gene and disease progression in NAFLD patients. Several other factors, such as advanced age, obesity, alcohol intake, insulin resistance and diabetes, are also exit in the disease progression.

\section{Conclusion}

In conclusion, the PNPLA3 GG genotype is a predisposing factor for the development of hepatic steatosis in NAFLD patients and related to a more severe liver disease. GG genotype is one of the predictive factors for disease progression.

Ethics Committee Approval: The Ankara University School of Medicine Clinical Research Ethics Committee granted approval for this study.

Peer-review: Externally peer-reviewed.

Author Contributions: Concept - RI, MB; Design - RI, SCK, AMB; Supervision - RI; Resource - RI, SCK, AMB; Materials - RI, SCK, GK, BS; Data Collection and/or Processing - RI, SCK, GK, AMB; Analysis and/or Interpretation - RI, SCK, GK, BS, AHE, AMB; Literature Search - RI, AMB; Writing - RI, AHE; Critical Reviews - RI, BS, AHE, MB.

Conflict of Interest: The authors have no conflict of interest to declare.

Financial Disclosure: The authors declared that this study has received no financial support.

\section{References}

1. Argo CK, Caldwell SH. Epidemiology and natural history of non-alcoholic steatohepatitis. Clin Liver Dis 2009;13(4):511-531.

2. Lazo M, Clark JM. The epidemiology of nonalcoholic fatty liver disease: a global perspective. Semin Liver Dis 2008;28(4):339-350.

3. Diehl AM, Day C. Cause, Pathogenesis, and Treatment of Nonalcoholic Steatohepatitis. N Engl J Med 2017;377(21):2063-2072.

4. Sheka AC, Adeyi O, Thompson J, Hameed B, Crawford PA, Ikramuddin S. Nonalcoholic Steatohepatitis: A Review. JAMA 2020;323(12):1175-1183.

5. Browning JD, Szczepaniak LS, Dobbins R, Nuremberg P, Horton JD, Cohen JC, et al. Prevalence of hepatic steatosis in an urban population in the United States: impact of ethnicity. Hepatology 2004;40(6):1387-1395.

6. Younossi ZM, Koenig AB, Abdelatif D, Fazel Y, Henry L, Wymer M. Global epidemiology of nonalcoholic fatty liver disease-Meta-analytic assessment of prevalence, incidence, and outcomes. Hepatology.2016;64(1):73-84.

7. Satman I, Omer B, Tutuncu Y, Kalaca S, Gedik S, Dinccag N, et al; TURDEP-II Study Group. Twelve-year trends in the prevalence and risk factors of diabetes and prediabetes in Turkish adults. Eur $\mathrm{J}$ Epidemiol 2013;28(2):169-180.

8. Younossi ZM. Non-alcoholic fatty liver disease - A global public health per- spective. J Hepatol 2019;70(3):531-544.

9. Yılmaz Y, Kanı HT, Demirtaş CÖ, Kaya E, Sapmaz AF, Qutranji L, et al. Growing burden of nonalcoholic fatty liver disease in Turkey: A single-center experience. Turk J Gastroenterol 2019;30(10):892-898.

10. Baulande S, Lasnier F, Lucas M, Pairault J. Adiponutrin, a transmembrane protein corresponding to a novel dietary- and obesity-linked mRNA specifically expressed in the adipose lineage. J Biol Chem 2001;276(36):3333633344.

11. Wilson PA, Gardner SD, Lambie NM, Commans SA, Crowther DJ. Characterization of the human patatin-like phospholipase family. J Lipid Res 2006;47(9):1940-1949.

12. Kienesberger PC, Oberer M, Lass A, Zechner R. Mammalian patatin domain containing proteins: a family with diverse lipolytic activities involved in multiple biological functions. J Lipid Res 2009;50 Suppl(Suppl):S63-68.

13. Kollerits B, Coassin S, Beckmann ND, Teumer A, Kiechl S, Döring A, et al. Genetic evidence for a role of adiponutrin in the metabolism of apolipoprotein B-containing lipoproteins. Hum Mol Genet 2009;18(23):4669-76.

14. Huang Y, He S, Li JZ, Seo YK, Osborne TF, Cohen JC, et al. A feed-forward loop amplifies nutritional regulation of PNPLA3. Proc Natl Acad Sci U S A 2010;107(17):7892-7897.

15. Romeo S, Kozlitina J, Xing C, Pertsemlidis A, Cox D, Pennacchio LA, et al. Genetic variation in PNPLA3 confers susceptibility to nonalcoholic fatty liver disease. Nat Genet 2008;40(12):1461-1465.

16. Valenti L, Alisi A, Galmozzi E, Bartuli A, Del Menico B, Alterio A, et al. I148M patatin-like phospholipase domain-containing 3 gene variant and severity of pediatric nonalcoholic fatty liver disease. Hepatology 2010;52(4):1274-1280.

17. Huang Y, Cohen JC, Hobbs HH. Expression and characterization of a PNPLA3 protein isoform (I148M) associated with nonalcoholic fatty liver disease. J Biol Chem 2011;286(43):37085-37093.

18. Liu YL, Patman GL, Leathart JB, Piguet AC, Burt AD, Dufour JF, et al. Carriage of the PNPLA3 rs738409 $\mathrm{C}>\mathrm{G}$ polymorphism confers an increased risk of non-alcoholic fatty liver disease associated hepatocellular carcinoma. J Hepatol 2014;61(1):75-81.

19. Kalia HS, Gaglio PJ. The Prevalence and Pathobiology of Nonalcoholic Fatty Liver Disease in Patients of Different Races or Ethnicities. Clin Liver Dis 2016;20(2):215-224.

20. Grimaudo S, Pipitone RM, Pennisi G, Celsa C, Cammà C, Di Marco V, et al. Association Between PNPLA3 rs738409 C $>$ G Variant and Liver-Related Outcomes in Patients With Nonalcoholic Fatty Liver Disease. Clin Gastroenterol Hepatol 2020;18(4):935-944.e3.

21. Kleiner DE, Brunt EM, Van Natta M, Behling C, Contos MJ, Cummings OW, et al; Nonalcoholic Steatohepatitis Clinical Research Network. Design and validation of a histological scoring system for nonalcoholic fatty liver disease. Hepatology 2005;41(6):1313-1321.

22. Aljanabi SM, Martinez I. Universal and rapid salt-extraction of high quality genomic DNA for PCR-based techniques. Nucleic Acids Res 1997;25(22):4692-4693.

23. World Health Organization. Report of a WHO consultation: definition of metabolic syndrome in definition, diagnosis and classification of diabetes mellitus. World Health Organization, Department of Noncommunicable Disease Surveillance. Geneva; 1999.

24. Matthews DR, Hosker JP, Rudenski AS, Naylor BA, Treacher DF, Turner RC. Homeostasis model assessment: insulin resistance and beta-cell function from fasting plasma glucose and insulin concentrations in man. Diabetologia 1985;28(7):412-419.

25. Ueno T, Sugawara H, Sujaku K, Hashimoto O, Tsuji R, Tamaki S, et al. Therapeutic effects of restricted diet and exercise in obese patients with fatty liver J Hepatol 1997;27(1):103-107.

26. Kukkonen K, Rauramaa R, Siitonen O, Hänninen O. Physical training of obese middle-aged persons. Ann Clin Res 1982;34:80-85.

27. Romeo S, Huang-Doran I, Baroni MG, Kotronen A. Unravelling the patho- 
genesis of fatty liver disease: patatin-like phospholipase domain-containing 3 protein. Curr Opin Lipidol 2010;21(3):247-252.

28. Hotta K, Yoneda M, Hyogo H, Ochi H, Mizusawa S, Ueno T, et al. Association of the rs738409 polymorphism in PNPLA3 with liver damage and the development of nonalcoholic fatty liver disease. BMC Med Genet 2010;11:172.

29. Sookoian S, Pirola CJ. Meta-analysis of the influence of I148M variant of patatin-like phospholipase domain containing 3 gene (PNPLA3) on the susceptibility and histological severity of nonalcoholic fatty liver disease. Hepatology 2011;53(6):1883-1894.

30. Chang CY. Understanding the relationship between PNPLA3, NAFLD and insulin resistance: do ethnic differences bring more questions or more answers? Liver Int 2011;31(9):1246-1249.

31. Kotronen A, Johansson LE, Johansson LM, Roos C, Westerbacka J, Hamsten A, et al. A common variant in PNPLA3, which encodes adiponutrin, is associated with liver fat content in humans. Diabetologia 2009;52(6):10561060.

32. Kantartzis K, Peter A, Machicao F, Machann J, Wagner S, Königsrainer $\mathrm{I}$, et al. Dissociation between fatty liver and insulin resistance in humans carrying a variant of the patatin-like phospholipase 3 gene. Diabetes 2009;58(11):2616-2623.

33. Petit JM, Guiu B, Masson D, Duvillard L, Jooste V, Buffier P, et al. Specifically PNPLA3-mediated accumulation of liver fat in obese patients with type 2 diabetes. J Clin Endocrinol Metab 2010;95(12):E430-436.

34. Valenti L, Al-Serri A, Daly AK, Galmozzi E, Rametta R, Dongiovanni P, et al. Homozygosity for the patatin-like phospholipase-3/adiponutrin I148M polymorphism influences liver fibrosis in patients with nonalcoholic fatty liver disease. Hepatology 2010;51(4):1209-1217.

35. Rotman Y, Koh C, Zmuda JM, Kleiner DE, Liang TJ; NASH CRN. The association of genetic variability in patatin-like phospholipase domain-containing protein 3 (PNPLA3) with histological severity of nonalcoholic fatty liver disease. Hepatology 2010;52(3):894-903.

36. Petta $S$, Grimaudo $S$, Cammà $C$, Cabibi D, Di Marco V, Licata G, et al. IL28B and PNPLA3 polymorphisms affect histological liver damage in patients with non-alcoholic fatty liver disease. J Hepatol 2012;56(6):13561362.

37. Zain SM, Mohamed R, Mahadeva S, Cheah PL, Rampal S, Basu RC, et al. A multi-ethnic study of a PNPLA3 gene variant and its association with disease severity in non-alcoholic fatty liver disease. Hum Genet 2012;131(7):11451152.

38. Argo CK, Northup PG, Al-Osaimi AM, Caldwell SH. Systematic review of risk factors for fibrosis progression in non-alcoholic steatohepatitis. J Hepatol 2009;51(2):371-379.

39. Bedogni G, Miglioli L, Masutti F, Tiribelli C, Marchesini G, Bellentani S. Prevalence of and risk factors for nonalcoholic fatty liver disease: the Dionysos nutrition and liver study. Hepatology 2005;42(1):44-52. 